\title{
Descrições, transferências e notas em Apomecynini (Coleoptera, Cerambycidae, Lamiinae)
}

\author{
Ubirajara R. Martins ${ }^{1,3}$ \\ Maria Helena M. Galileo ${ }^{2,3}$
}

\begin{abstract}
Descriptions, transferences and notes on Apomecynini (Coleoptera, Cerambycidae, Lamiinae). The following new species are described from Brazil: Falsischnolea apicalis sp. n., Dorcasta singularis sp. $\mathbf{n}$. and Paraesylacris candida sp. n. and from Venezuela: Amphicnaeia piriana sp. n. and A. zonata sp. n. New synonyms established: Acestrilla apicalis Breuning, 1942 and A. strandiella Breuning, $1943=$ A. minima Bates, 1885. Bisaltes acutipennis Thomson, 1868 is transferred to the genus Ataxia Haldeman, 1847 (Pteropliini). Falsestola Breuning, 1940 is considered a synonym of Hesycha Fairmaire \& Germain, 1859 and transferred to the tribe Onciderini. Hesycha ocellifera Martins \& Galileo, 1990 is synonymized with Hesycha inermicollis (Breuning, 1940).

KEY WORDS. Apomecynini, Onciderini, Pteropliini, new species, synonym, transference
\end{abstract}

Espécies americanas da tribo Apomecynini foram revistas por BREUNING (1971) que apresentou chave para gêneros e redescrições de todas as espécies. Examinou-se o material desta tribo pertencente ao Museu de Zoologia da Universidade de São Paulo, São Paulo (MZSP), ao Museu de Ciências Naturais, Porto Alegre (MCNZ) e à Facultad de Agronomia Universidad Central de Venezuela, Maracay (MIZA) e chegou-se a algumas observações que são publicadas a seguir.

\section{Apomecynini}

\section{Acestrilla minima Bates, 1885}

Acestrilla minima Bates, 1885: 350, est. 22, fig. 12; Monné, 1994a: 2 (cat).

Acestrilla strandiella Breuning, 1942: 140. Syn. n.

Acestrilla annulicornis Breuning, 1943: 38. Syn. n.

A espécie-tipo do gênero Acestrilla Bates, 1885, A. minima Bates, 1885, foi descrita originalmente da Guatemala, Vera Paz, Panima e do Panamá, Chiriqui, Vulcão Chiriqui. CHEMSAK \& LinSLEY (1970), ao designar lectótipo, restringiram a localidade-tipo para Vulcão Chiriqui. BREUNING (1971: 214) reviu as espécies de Acestrilla e assinalou A. minima para o Brasil (Rio de Janeiro e Nova Friburgo).

1) Museu de Zoologia, Universidade de São Paulo. Caixa Postal 42649, 04299-970 São Paulo, São Paulo, Brasil.

2) Museu de Ciências Naturais, Fundação Zoobotânica do Rio Grande do Sul. Caixa Postal 1188, 90001-970 Porto Alegre, Rio Grande do Sul, Brasil. E-mail: galileo@ pampa.tche.br

3) Pesquisador do Conselho Nacional de Desenvolvimento Científico e Tecnológico (CNPq). 
No mesmo trabalho, BREUNING (1971: 213) apresentou chave para identificar as três espécies de Acestrilla: A. minima, A. strandiella Breuning, 1942 e A. annulicornis Breuning, 1943. Para distinguir A. minima das outras duas espécies utilizou o comprimento do antenômero IV em relação ao $\mathrm{V}$ : igual ao $\mathrm{V}$ para $A$. minima e um pouco mais longo que o $\mathrm{V}$ para $A$. annulicornis e $A$. strandiella. Esse caráter não parece consistente e é de difícil avaliação, o que justifica a sinonímia proposta.

Para diferenciar A. strandiella de A. annulicornis foram utilizados a cor da borda anterior do pronoto e a cor dos élitros. Ambas as espécies foram descritas de Santa Catarina e verificou-se que essas cores variam bastante. Portanto, considerou-se apropriado considerá-las coespecíficas.

Material examinado. BrasiL, Rio de Janeiro: Rio de Janeiro, fêmea, Acc. 2966 (ret. do CMNH, MCNZ). Santa Catarina: Ilha do Arvoredo, 2 fêmeas, X.1994, A. Franceschini leg. (MCNZ); Rancho Queimado, macho, X.1994, L. Moura leg. (MCNZ); macho, XI.1994, L. Moura leg. (MCNZ); macho, 2 fêmeas, XI.1995, L. Moura leg. (MCNZ). Rio Grande do Sul: Itaúba (Ponto 10), macho, X.1999, Franceschini, Bonaldo \& Silva leg. (MCNZ):

\section{Falsischnolea apicalis sp. $\mathbf{n}$.}

Fig. 1

Cabeça com tegumento castanho-avermelhado. Fronte e vértice com pontuação alveolada (32x). Pequeno tufo de pubescência branca entre os tubérculos anteníferos. Lobos oculares superiores pouco mais distantes entre si do que a largura de um lobo; lobos oculares inferiores com o dobro do comprimento das genas. Antenas avermelhadas, o escapo mais escuro com comprimento subigual ao do corpo nos dois sexos. Antenômero IV mais longo do que o III. Protórax castanhoavermelhado. Pronoto com faixa central de pubescência branca no terço basal; com pontos moderadamente esparsos (40x) e alguns pêlos brancos, esparsos. Escutelo revestido por pubescência branca densa. Élitros vermelho-acastanhados; triângulo basal, circum-escutelar, indistintamente mais escurecido; terço apical alaranjado. Élitros com longas setas escuras e brancas; inteiramente recobertos por pubescência esbranquiçada uniforme. Pernas avermelhadas com longos pêlos esbranquiçados.

Dimensões mm, respectivamente macho/fêmea. Comprimento do protórax, 1,0-1,2/1,1-1,4; maior largura do protórax, 1,0-1,2/1,2-1,5; comprimento do élitro, 2,9-3,6/3,5-4,3; largura umeral, 1,2-1,5/1,5-1,8.

Material-tipo. Holótipo fêmea, BRASIL, Espírito Santo: Linhares, XI.1972, P.C. Elias leg. (MZSP). Parátipos - fêmea, mesmos dados do holótipo (MZSP); 2 fêmeas, 4 machos, mesma localidade, X.1972, mesmo coletor (MZSP); macho, mesma localidade, XII.1972, mesmo coletor (MCNZ).

Discussão. Falsischnolea apicalis assemelha-se a F. flavoapicalis, que apresenta uma mancha alaranjada ante-apical e uma pubescência acinzentada concentrada numa faixa oblíqua que percorre a metade anterior dos élitros dos úmeros até a sutura. Em F. apicalis, a mancha alaranjada ocupa todo o terço apical dos élitros e a pubescência da metade anterior é esbranquiçada uniformemente distribuída. 

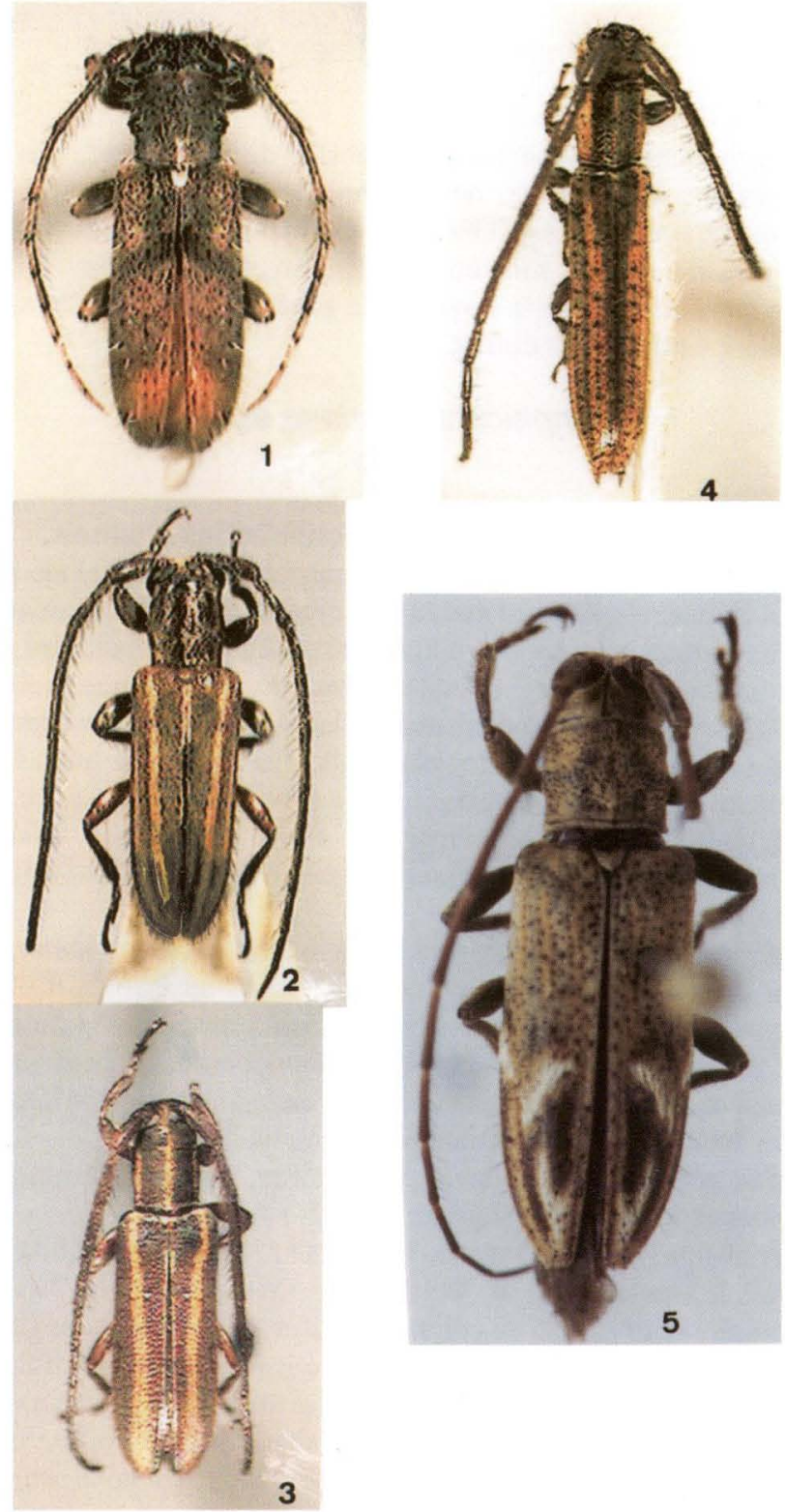

Figs 1-5. (1) Falsischnolea apicalis, parátipo fêmea, Linhares, Espírito Santo, Brasil, comprimento $5.9 \mathrm{~mm}$; (2) Amphicnaeia piriana, holótipo macho. Rancho Grande. Aragua, Venezuela. comprimento 5,4 mm; (3) Amphicnaeia zonata, holótipo fêmea, Rancho Grande, Aragua, Venezuela, comprimento $7,8 \mathrm{~mm}$; (4) Dorcasta singularis, holótipo macho Dianópolis, Goiás, Brasil, comprimento 7,6 mm; (5) Paraesylacris candida, holótipo fêmea, Xapuri (Pimenteira), Acre, Brasil, comprimento, $10,0 \mathrm{~mm}$. 


\section{Amphicnaeia Bates, 1866}

Amphicnaeia Bates, 1866: 32; Monné, 1994a: 3 (cat.).

O gênero reunia 17 espécies até o trabalho de MARTINS \& GALILEO (1999) quando foi descrita $A$. flavescens da Colômbia amazônica. GALILEO \& MARTINS (no prelo) revalidaram três espécies e descreveram mais cinco, quatro da Mata Atlântica no Brasil e uma, A. tate, do Equador. Ao estudar-se o material da MIZA, descobriu-se mais duas espécies novas deste gênero, ambas com faixas longitudinais, contínuas e estreitas nos élitros.

\section{Amphicnaeia piriana sp. $\mathbf{n}$.}

Fig. 2

Etimologia. Tupi, piriana = listado, alusivo às faixas elitrais.

Tegumento castanho-avermelhado, recoberto por pilosidade acastanhada. Metafêmures com a metade basal mais avermelhada. Pubescência amarelada reveste: genas, área estreita ao redor dos olhos, vértice (entre os tubérculos anteníferos), faixa atrás dos olhos; faixa longitudinal nos lados do protórax que se continua pelos mesepimeros, mesepisternos, metepisternos, lados do metasterno e lados dos urosternitos; pronoto com três faixas longitudinais, duas laterais e uma, mais estreita, central; escutelo; cada élitro com estreita faixa sutural da base ao terço apical; faixa longitudinal, que se inicia entre o úmero e o escutelo e atinge o ápice; uma faixa sobre a declividade lateral do terço basal até quase o ápice; borda apical com estreita faixa em forma de V.

Fronte com duas sencilas junto à borda interna dos lobos oculares inferiores. Vértice com duas sencilas junto aos lobos oculares superiores. Lobos oculares superiores com sete fileiras de omatídios mais próximos entre si do que a largura de um lobo. Protórax sem espículo lateral. Pronoto pontuado, com quatro sencilas equiidistantes a cada lado, inseridas no interior da faixa amarelada lateral. Metatarsômeros com dois terços do comprimento das metatíbias.

Dimensões (mm). Comprimento do protórax, 1,1; maior largura do protórax, 1,1; comprimento do élitro, 4,0; largura umeral, 1,6.

Material-tipo. Holótipo macho, VenezUELA, Aragua: Rancho Grande (1100 m), 8.XI.1967, F. Fernandez \& B. Villasnil leg. (MIZA).

Discussão. Pelo padrão de colorido, A. piriana assemelha-se a A. flavescens Martins \& Galileo, 1999. Difere, segundo a descrição, pela faixa elitral, estreita, que se inicia entre o úmero e o escutelo e prolonga-se até a ponta; pela faixa sutural que também percorre todo élitro; pelas bases dos metafêmures avermelhadas. Em $A$. flavescens a faixa que se inicia entre o úmero e o escutelo e a faixa sutural terminam no meio do élitro e os metafêmures são unicolores.

Distingue-se de A. albovittata Breuning, 1971, descrita do Rio de Janeiro, por não apresentar faixa longitudinal, larga, junto da sutura. Em A. piriana a faixa mais larga dos élitros inicia-se entre o úmero e o escutelo.

Amphicnaeia piriana e A. quinquevittata apresentam cinco faixas claras longitudinais nos élitros e assemelham-se bastante. Amphicnaeia piriana apresenta uma faixa longitudinal na declividade lateral do élitro entre a faixa dorsal e a faixa 
marginal e não tem faixa junto ao friso marginal. Em A. quinquevittata Bates, 1885, não existe faixa longitudinal entre a faixa dorsal e a faixa marginal.

\section{Amphicnaeia zonata sp. $\mathbf{n}$.}

Fig. 3

Tegumento vermelho-acastanhado. Cabeça revestida por pubescência castanha com algum reflexo púrpura; pubescência amarelada reveste a parte inferior da fronte, faixa atrás dos olhos e estreita faixa longitudinal que percorre o vértice. Lobos oculares inferiores mais longos do que as genas. Lobos oculares superiores tão distantes entre si quanto a largura de um lobo. Tubérculos anteníferos salientes. Antenas inteiramente castanho-avermelhadas, atingem as extremidades elitrais na ponta do antenômero X. Antenômeros II a XI (especialmente os III a V) com franja de pêlos pretos, muito densa, no lado inferior. Escapo com tegumento avermelhado no lado externo do terço apical.

Pronoto com três faixas longitudinais de pubescência amarelada, estreitas e da mesma largura: uma no meio do dorso e duas laterais. Lados do protórax com faixa larga de pubescência amarelada, que se continua para a parte posterior pelo mesepimero, mesepisterno, metepimero, metepisterno e lados dos urosternitos. Escutelo revestido por pubescência amarelada.

Élitros com pubescência arroxeada com reflexos iridescentes. Friso sutural revestido, estreitamente, por pubescência amarelada; uma faixa amarela que se inicia entre o úmero e o escutelo (mais próxima daquele), relativamente larga, vai até ápice; uma terceira faixa, também amarelada, junto ao friso marginal do quarto anterior ao ápice onde se une com a faixa dorsal. Extremidades elitrais arredondadas. Setas pretas localizadas principalmente na metade apical dos élitros. Profêmures fusiformes; mesoe metafêmures, sem setas, pedunculados e clavados. Tíbias e tarsos avermelhados.

Dimensões, em mm. Comprimento do protórax, 1,3; maior largura do protórax, 1,4; comprimento do élitro, 5,9; largura umeral, 2,0.

Material-tipo. Holótipo fêmea, Venezuela, Aragua: Rancho Grande (1100 m), 18.VII.1949, F. Fernandez \& P. Fenize leg. (MIZA).

Discussão. Amphicnaeia zonata difere de A. quinquevittata Bates, 1885 pelas faixas elitrais: a sutural restringe-se ao friso e entre as faixas dorsal e lateral não existe faixa; em A. quinquevittata a faixa sutural é mais larga e avança além do friso, e encontra-se uma faixa adicional entre a faixa dorsal e a lateral (BREUNING 1971: 221).

Em A. bivittata Melzer, 1933, que tem desenho elitral semelhante, a região pós-ocular e o pronoto têm os lados com pubescência rósea. Em A. zonata não existe pubescência rosada.

\section{Dorcasta singularis sp. $\mathbf{n}$.}

Fig. 4

Tegumento avermelhado ou castanho-avermelhado. Fronte e genas revestidas por pubescência esbranquiçada e densa. Lados da cabeça com duas faixas longitudinais de pubescência amarelada. Região central do vértice sem f́aixa de 
pubescência. Antenas inteiramente castanho-avermelhadas. Protórax com cinco faixas longitudinais de pubescência amarelada: uma estreitíssima no meio, duas mais largas nos lados do disco pronotal e duas nas partes laterais do protórax, continuadas pelos mesepisternos, mesepimeros, partes laterais do metasterno, metepisterno e lados dos urosternitos. Élitros com uma faixa sutural castanho-avermeIhada, muito esparsamente pubescente, iniciada na base entre o úmero e o escutelo, adelgaçada no quinto anterior e gradualmente mais estreitada até antes do ápice; essa faixa envolve uma fileira de setas pretas; uma faixa larga, de pubescência ocrácea,da base, ao lado da faixa acastanhada, até o ápice; essa faixa envolve uma fileira de pontos contrastantes que se inicia na base entre a faixa amarelada e a faixa sutural; uma faixa estreita da coloração do fundo representada por pontos glabros e eqüidistantes; faixa esbranquiçada da base ao sexto apical; outra faixa glabra representada por pontos; outra faixa amarelada sob os úmeros até o ápice onde se funde com a faixa amarelada dorsal; uma faixa glabra lateral com uma fileira de setas. Extremidades elitrais com espinho externo e espículo no ângulo sutural. Lado inferior do corpo e fêmures com pubescência esbranquiçada.

Dimensões (mm). Comprimento do protórax, 1,0; maior largura do protórax, 1,2; comprimento do élitro, 5,5; largura umeral, 1,4.

Material-tipo. Holótipo macho, BRASIL, Goiás: Dianópolis, 16-22.I.1962, J. Bechyné leg. (MZSP).

Discussão. Dorcasta singularis não pode ser confundida com $D$. dasicera (Erichson, 1848) que também apresenta faixas amareladas e brancas nos élitros, porque o friso sutural tem faixa amarelada; as duas faixas amareladas intercaladas pelas faixas esbranquiçadas são mais estreitas e as faixas acastanhadas são de mesma largura. Difere de D. implicata Melzer, 1934 e D. quadrispinosa Breuning, 1940 pelo aspecto da faixa sutural e da faixa branca nos élitros. É semelhante também a D. gracilis Fisher, 1932, descrita do Haiti, pela ausência de faixa amarela no friso sutural, mas nessa espécie os espinhos do ápice elitral são convergentes.

\section{Paraesylacris candida sp. $\mathbf{n}$.}

Fig. 5

Tegumento vermelho-acastanhado. Cabeça inteiramente revestida por pubescência amarelo-acastanhada. Lobos superiores do olhos com seis fileiras de omatídios, tão distantes entre si quanto a largura de duas fileiras de omatídios. Lobos oculares inferiores três vezes mais longos do que as genas. Antenas revestidas por pubescência esbranquiçada esparsa; atingem o ápice dos élitros aproximadamente na ponta do antenômero IX. Escapo subcilíndrico. Antenômero III apenas mais curto que o IV. Protórax mais largo do que longo, revestido por pubescência amareloacastanhada com tubérculo pequeno no meio dos lados. Pronoto com três gibosidades muito discretas; pontuação evidente, os pontos pequenos e moderadamente densos. Partes laterais do protórax com o mesmo tipo de pontuação.

Élitros com a metade anterior revestida por pubescência amarelo-acinzentada com três faixas pouco contrastantes de pubescência amarelo-alaranjada e com desenhos de pubescência branca logo atrás do meio: faixa curta, oblíqua, em sentido 
descendente da sutura para a margem mais ou menos ligada a outra faixa oblíqua em sentido descendente da margem para a sutura; estas duas faixas examinadas em conjunto lembram uma letra $\mathrm{V}$; uma outra faixa de pubescência branca no dorso do quinto apical paralela à margem quase atinge o ápice elitral. Três áreas acastanhadas longitudinais no terço posterior: uma entre as faixas brancas, uma no lado externo da faixa apical e outra paralela à margem. Crista centro-basal indicada, representada por gibosidade arredondada no topo. Extremidades obliquamente truncadas.

Pernas e face ventral recobertas por pubescência amarelo-acastanhada. Urosternitos com faixas castanhas perto da margem lateral.

Dimensões (mm). Comprimento do protórax, 1,7; maior largura do protórax, 2,2; comprimento do élitro, 7,0; largura umeral, 2,4.

Material-tipo. Holótipo fêmea, BRASIL, Acre: Xapuri (Pimenteira), 5-7.IV. 1996, A. Brescovitt leg. (MZSP).

Discussão. Difere de P. bituberosa Breuning, 1940 pela ausência de crista desenvolvida, centro-basal nos élitros e pelos desenhos constituídos pela pubescência branca na metade apical dos élitros. Em P. bituberosa as faixas são longitudinais com exceção das centrais que são oblíquas e descendentes da margem para a sutura. Em P. columbiana Breuning, 1940, a metade apical dos élitros é inteiramente amarelo-acastanhada.

\section{Pteropliini}

\section{Ataxia acutipennis (Thomson, 1868) comb. $\mathbf{n}$.}

Bisaltes acutipennis Thomson, 1868: 111.

Bisaltes (B.) acutipennis; Breuning, 1960: 178 (cat.); Monné, 1994a: 20 (cat.).

Como Bisaltes Thomson, 1864, Ataxia também possui cicatriz no escapo. A configuração do pronoto de Ataxia acutipennis permite transferir esta espécie para o gênero Ataxia, como já havia anotado R. C. Marinoni à margem da moldura do diapositivo do tipo de Bisaltes acutipennis: "= Ataxia prolixa Bates". Estamos seguros que $B$. acutipennis deve ser transferida para Ataxia, mas não se pode afirmar que se trata de um sinônimo de A. prolixa (Bates, 1866).

\section{Onciderini}

\section{Hesycha Fairmaire \& Germain, 1859}

Hesycha Fairmaire \& Germain, 1859: 523: Monné, 1994b: 18 (cat.)

Falsestola Breuning, 1940: 155; Monné, 1994a: 13 (cat.). Syn. n.

Estolosybra Breuning, 1943: 41; Breuning, 1971: 251 (Syn.).

Ao examinar-se o diapositivo do holótipo, fotografado por J.S. Moure no Museu de Paris de Falsestola inermicollis Breuning, 1940 (Apomecynini), constatou-se que pertence ao gênero Hesycha da tribo Onciderini. Embora não se tenha examinado $F$. strandi (Breuning, 1943), da Venezuela, que é a outra espécie incluída em Falsestola por Breuning (1971), julga-se apropriado também transferí-la para Hesycha. 


\section{Hesycha inermicollis (Breuning, 1940) comb. $\mathbf{n}$.}

Falsestola inermicollis Breuning, 1940: 115; Monné, 1994a: 13 (cat.).

Hesycha ocellifera Martins \& Galileo 1990: 74, figs 1, 33; Monné, 1994b: 19 (cat). Syn. n.

O holótipo de Falsestola inermicollis, descrito de Santo Antonio da Barra, hoje Condeuba, Bahia, é uma fêmea na qual os tubérculos anteníferos não são projetados como nos machos com tubérculos curtos e muito agudos.

A espécie ocorre no Brasil, da Bahia ao Paraná e na Argentina, Misiones.

Material examinado, além da série-típica de Hesycha ocellifera. BRASIL, Espírito Santo: Linhares, macho, X.1972, P.C. Elias leg.; São Paulo: Atibaia, macho, X.1969, J. Halik leg.; Barueri, macho, IX.1954, K. Lenko leg.; macho, X.1965, K. Lenko leg.; macho, fêmea, XI.1966, K. Lenko leg.; Campinas, macho, IX.1937, H. Sauer leg.; Itu (Fazenda Pau d'Alho), fêmea, IX.1959, U. Martins leg.; Osasco, fêmea, XI.1964, M.A. Vulcano leg.; São Paulo (Brooklin Paulista), fêmea, X.1966, L. Travassos Filho leg.; Santa Catarina: Seara (Nova Teutônia, 27²11'S, $52^{\circ} 23^{\prime}$ W), macho, XI.1934, F. Plaumann leg.

\section{Hesycha strandi (Breuning, 1943) comb. $\mathbf{n}$.}

Estolosybra strandi Breuning, 1943: 41.

Falsestola strandi; Breuning, 1971: 252; Monné, 1994a: 13 (cat.).

AGRADECIMENTOS. Ao Dr. Renato C. Marinoni, Universidade Federal do Paraná, pelo empréstimo dos diapositivos dos tipos. Ao bolsista de Iniciação Científica, Fundação de Amparo à Pesquisa do Estado do Rio Grande do Sul, Jorge Dutra Soledar, pela execução das fotografias.

\section{REFERÊNCIAS BIBLIOGRÁFICAS}

Bates, H.W. 1866. Contributions to on insect fauna of the Amazon Valley. Coleoptera. Longicornia. An. Mag. Nat. Hist. (3) 17: 31-42.

. 1885. Biologia Centrali-Americana. Insecta, Coleoptera, suppl. to Longicornia. London,

5, p. 249-436.

Breuning, S. 1940. Novae species Cerambycidarum. IX. Folia Zool. Hydrobiol., Riga, 10: 115-214. 1942. Novae species Cerambycidarum. XI. Folia Zool. Hydrobiol., Riga, 11: 113-175. 1943. Novae species Cerambycidarum. XII. Folia Zool. Hydrobiol., Riga, 12: 12-66. 1960. Catalogue des Lamiaires du Monde (Col., Cerambycidae). 3 Lief. Tutzing bei München, Mus. G. Frey, p. 109-182.

- 1971. Révision des espèces américaines de la tribue des Apomecynini Lac. (Coleoptera, Cerambycidae). Entomol. Abhand. Staat. Mus. Tierk., Dresden, 37 (3): 209-235.

Fairmaire, L. \& P. Germain. 1859. Révision des coléoptères du Chili (suite). Ann. Soc. ent. France, Paris, (3) 7: 483-532.

Galileo, M.H.M. \& U.R. MARTins (no prelo). Notas sobre Amphicnaeia Bates, 1866 (Coleoptera, Cerambycidae, Lamiinae) com revalidações e descrição de espécies novas. Revta bras. Ent., Curitiba.

Chemsak, J.A. \& E.G. Linsley. 1970. Additional designations of lectotypes of neotropical Cerambycidae in the collections of the British Museum (Natural History) (Coleoptera). Jour. Kansas Ent. Soc., Manhattan, 43 (4): 404-417.

Martins, U.R. \& M.H.M. Galileo. 1990. Onciderini (Coleoptera, Cerambycidae, Lamiinae): 
sinonímias, novos táxons, chaves e notas. Papéis Avuls Zool., São Paulo, 37 (4): 53-95.

1999. Sobre algumas espécies de Lamiinae (Coleoptera, Cerambycidae) da Colômbia com garras tarsais divergentes. Papéis Avuls Zool., São Paulo, 41 (5): 67-81.

Monné, M.A. 1994a. Catalogue of the Cerambycidae (Coleoptera) of the Western Hemisphere Part XIV. São Paulo, Soc. Bras. Ent., 72p.

- 1994b. Catalogue of the Cerambycidae (Coleoptera) of the Western Hemisphere Part XV. São Paulo, Soc. Bras. Ent., 108p.

Thomson, J. 1868. Matériaux pour servir a une révision des Desmiphorites (Lamites, Cérambycides, Coléoptères). Physis Rec. Hist. Nat., Paris, 2 (6): 101-146.

Recebido em 14.II.2001; aceito em 26.X.2001 